\section{Adverse drug reactions: a potential role for pharmacists}

I read the editorial by Howe that mentioned the risk to patient safety of medication reconciliation errors between hospitals and general practices. ${ }^{1}$ During my placements in hospitals, I noticed one of the most frequent errors is patients' adverse drug reactions (ADR) not being properly documented. Patients are sometimes mistakenly given medications which had caused ADR in the past. It has been suggested that closer collaboration between doctors and pharmacists in primary care prevent ADR. ${ }^{2}$ In Oceania, data showed that patients' charts reviewed by pharmacists were less likely to have inadequate documentations of ADR (13.5\% versus $29.4 \%$; $P<0.001) .{ }^{3}$

Being an ex-pharmacist and now a medical doctor, I conducted a study that investigated how many ADRs were missed or incompletely documented in the admission medical notes in New Cross Hospital, Wolverhampton. From September to November 2013, I interviewed 109 consecutive adult inpatients, who were alert and oriented with Glasgow Coma Scale score of 15 (Table 1). Participants were interviewed using a list of questions adapted from a previously published questionnaire. ${ }^{4}$ Participants were asked to list any drugs they could not tolerate and describe the nature of reactions. The collected information was compared with the ADR history in the admission notes documented by doctors. Only reactions listed in standard texts (British National Formulary and Lexi-Comp ${ }^{\circledR}$ ) are regarded as likely reactions.

\section{Table 1. Patient demographics ${ }^{\mathrm{a}}$}

\begin{tabular}{lcc} 
& $\boldsymbol{n}$ & $\%$ \\
\hline Male patients & 57 & 52.3 \\
\hline Female patients & 52 & 47.7 \\
\hline General ward & 23 & 21.1 \\
\hline Cardiology/stroke ward & 16 & 14.7 \\
\hline Gastroenterology ward & 9 & 8.3 \\
\hline Endocrinology ward & 12 & 11.0 \\
\hline Respiratory ward & 31 & 28.4 \\
\hline Renal ward & 18 & 16.5 \\
\hline
\end{tabular}

Mean age (standard deviation) 66 (16.4) years
Fifty-two of the 109 patients (47.7\%) reported an ADR to at least one drug. ADR documentation was inadequate in 39 patient notes (35.8\%): absent in 20 and without the nature of the reaction in 19 . The result in the current study was comparable to the $29.4 \%$ of inadequate ADR documentations when pharmacists were not involved found in the Oceanian study. ${ }^{3}$ These suggest that pharmacist involvement in drug historytaking and ADR assessment can potentially reduce medication errors. This hypothesis needs to be validated with prospective studies and should include pharmacist involvement and better education in therapeutics and in communication skills. Having more pharmacist involvement in hospital and primary care could improve medication reconciliation.

\section{Eugene $\mathrm{YH}$ Yeung,}

College of Medical and Dental Sciences, University of Birmingham, Birmingham.

E-mail: eugeneyhlagmail.com

\section{REFERENCES}

1. Howe A. Patient safety: the general practice agenda. Br J Gen Pract 2015; DOI: 10.3399/bjgp15X684673.

2. Shulman JI, Shulman S, Haines AP. The prevention of adverse drug reactions - a potential role for pharmacists in the primary care team? J R Coll Gen Pract 1981; 31(228): 429-434.

3. Barton L, Futtermenger J, Gaddi Y, et al. Simple prescribing errors and allergy documentation in medical hospital admissions in Australia and New Zealand. Clin Med 2012; 12(2): 119-123.

4. Cook M, Ferner RE. Adverse drug reactions: who is to know? BMJ 1993: 307(6902): 480-481.

DOI: 10.3399/bjgp15X68682

\section{Evidence-based medicine and dementia}

Claire Hilton describes how NHS policy in the current dementia crusade could distort good clinical practice. ${ }^{1}$ I think the departure from evidence-based medicine is even greater than she suggests.

Case finding for dementia was introduced when there was no evidence (beyond anecdotes) that it was beneficial. We have known for a decade that screening for memory loss identifies less than one in five of those who will subsequently develop dementia syndrome. ${ }^{2}$ We now have evidence that early psychosocial intervention has no effect on relocation to a care home, patient wellbeing, disease progression, dementiarelated symptoms, or caregiver wellbeing. ${ }^{3}$

We have no evidence that memory clinics are the best way to reach diagnoses ${ }^{4}$ and grounds for thinking that their resources might be better used to manage dementia's behavioural and psychological symptoms. We do not know that earlier recognition and intervention is harmless, ${ }^{4}$ and there seems little interest in finding out. We might be concerned that dementia now overshadows other problems of ageing, like depression and frailty.

We do know that the incidence and prevalence of dementia syndrome appear to be declining in many countries, including Britain, ${ }^{5}$ Germany, Spain, Sweden, the Netherlands, and the US.6 This may mean that prevention of cardiovascular disease is having an effect on brains. GPs' performance in recognising dementia may be underestimated because of over-estimation of prevalence.

We have seen how poorly-evaluated, short-term projects to provide support or signposting have burgeoned and then disappeared; the familiar NHS disorder of 'multiple projectitis'. And we also know that drug development has failed for a generation, with no symptom modifiers better than cholinesterase inhibitors, no disease modifiers at all, and no prospect of a 'cure' despite lots of 'promising' studies. We do not appear to understand the underlying pathological processes, have over-valued protein unfolding and deposition, and have undervalued the role of neuroprotection pathways. $^{?}$

The Dementia crusade has been endorsed by politicians, particularly the Prime Minister. This has allegedly brought rising 'awareness' of dementia, and has yielded benefits for professionals and charities. Its effects on those with dementia are less clearly visible.

Steve Illiffe,

Professor of Primary Care for Older People, University College London.

E-mail: s.iliffeluucl.ac.uk

\section{Competing interests}

Member of the Alzheimer's Society; member of the NICE/SCIE Dementia clinical guidelines development 
group 2004-2006; associate director of the national Dementias \& Neurodegenerative Diseases Research Network (DENDRON) 2006-2015; working group chair for the National Dementia Strategy 2009.

\section{REFERENCES}

1. Hilton C. Dementia, screening, targets and incentives. Br J Gen Pract 2015; DOI: 10.3399/bjgp15X685969.

2. Palmer K, Bäckman L, Winblad B, et al. Detection of Alzheimer's disease and dementia in the preclinical phase: population based cohort study. BMJ 2003; 326(7383): 245

3. Koivisto AM, Hallikainen I, Välimäki T, et al. Early psychosocial intervention does not delay institutionalization in persons with mild Alzheimer disease and has impact on neither disease progression nor caregivers' well-being: ALSOVA 3-year follow-up. Int J Geriatr Psychiatry 2015; doi: 10.1002/gps.4321. [Epub ahead of print]

4. Le Couteur DG, Doust J, Creasey H, Brayne C. Political drive to screen for pre-dementia: not evidence based and ignores the harms of diagnosis. BMJ 2013; 347: 55125 .

5. Matthews FE, Arthur A, Barnes LE, et al. A twodecade comparison of prevalence of dementia in individuals aged 65 years and older from three geographical areas of England: results of the Cognitive Function and Ageing Study I and II. Medical Research Council Cognitive Function and Ageing Collaboration. Lancet 2013; 382(9902): 1405-1412

6. Prince M, Albanese E, Guerchet M, et al. World Alzheimer Report 2014. Dementia and risk reduction: an analysis of protective and modifiable factors. London: Alzheimer's Disease International, 2014.

7. Andrade-Moraes $\mathrm{CH}$, Oliveira-Pinto AV, CastroFonseca $\mathrm{E}$, et al. Cell number changes in Alzheimer's disease relate to dementia, not to plaques and tangles. Brain 2013; 136: 3738-3752.

DOI: 10.3399/bjgp15X686833

\section{Honouring the patient}

Davidson writes excellently about the risk of too much medicine in Oman and the Middle East suggesting that this may be related to traditional Arab culture that seeks to please or satisfy a guest. ${ }^{1}$

This is known as Ikram ad-Daif, an Arabic phrase which can be translated as 'honouring one's guest'; one of the most established practices in Arab and the wider Muslim tradition. Application of this may, indeed, make it difficult for doctors to refuse unrealistic and inappropriate patient requests, fuelling rising patient expectations.

However, it is noteworthy to remember, that honouring someone is also to fulfil one's obligation to them. Core medical principles such as effective communication and shared decision making should be applied alongside sensible and judicious medical investigation and prescribing; this would be, in my opinion, truly honouring one's guest and fulfilling one's obligation towards them and the healthcare system as a whole.

Faraz Mughal,

GP, Solihull, West Midlands.

E-mail: farazmadoctors.org.uk

\section{REFERENCE}

1. Davidson R. Too much medicine in the Middle East? Br J Gen Pract 2015; DOI: 10.3399/bjgp15X686197.

DOI: 10.3399/bjgp15X686845

\section{Low vitamin D prevalence at the GP practice}

There was recently a recommendation by the Scientific Advisory Committee on nutrition that suggests everyone from the age of 1 year should take vitamin D supplements. ${ }^{1}$ The plan is still in consultation, but it highlights the high prevalence of vitamin $D$ deficiency in the population. ${ }^{2}$ We have conducted a study of the prevalence of low vitamin $D$ at Garswood general practice surgery, in Northwest England. We took the value of $75 \mathrm{nmol} / \mathrm{l}$ as the cut-off for low in vitamin D level. A total of 302 patients had their vitamin $D$ level checked, of which an average of $90 \%$ across all age groups had low vitamin D.

The findings correlates with a global metaanalysis study, where close to $90 \%$ of the samples had levels $<75 \mathrm{nmol} / \mathrm{l}$, although variability exists across region, sex and age. We used the $75 \mathrm{nmol} / \mathrm{l}$ level as a cut-off as a matter of simplicity for comparison, but we are aware of the ambiguity that still exists about the absolute cut-off level defined as low vitamin $D . .^{4-5}$ In view of the recent findings and recommendation, we believe we should look into devising a systematic way of screening and supplementing everyone with vitamin D.

\section{Lee Wah Phin,}

Core Medical Trainee, Southport and Formby District General Hospital.

E-mail: wahphin2005layahoo.com.my

John Holden,

GP, Garswood Surgery, Wigan.

\section{REFERENCES}

1. Scientific Advisory Committee on Nutrition. Draft Vitamin D and Health Report. Scientific consultation: July to September 2015. https://www.gov.uk/ government/uploads/system/uploads/attachment_ data/file/447402/Draft SACN Vitamin D and Health_Report.pdf (accessed 4 Sep 2015).

2. Davies JS, Poole CD. Vitamin D: too much of a good thing? Br J Gen Pract 2014; DOI: 10.3399/ bjgp14X676276

3. Hilger J, Friedel A, Herr R, et al. A systematic review of vitamin $\mathrm{D}$ status in populations worldwide. $\mathrm{Br} \mathrm{J}$ Nutr 2014; 111: 23-45.

4. National Osteoporosis Society. Vitamin D and bone health: a practical clinical guideline for patient management. Bath: National Osteoporosis Society, 2013.

5. Vieth R. Why the minimum desirable serum 25-hydroxyvitamin D level should be $75 \mathrm{nmol} / \mathrm{L}$ (30 $\mathrm{ng} / \mathrm{ml}$. Best Pract Res Clin Endocrinol Metab 2011; 25: 681-691.

DOI: 10.3399/bjgp15X686857

\section{AJ Cronin}

I enjoyed the articles about the distinguished author AJ Cronin in the September issue. ${ }^{1-2}$ However, in these days of concerns about how we treat whistle-blowers, an important and telling piece of information was omitted by both authors.

By writing about the 'humbug' of private medicine in the 1930s, Dr Cronin became persona non grata to a significant swathe of the medical establishment. When he died in 1981, 44 years after the publication of The Citadel, his obituary in the Lancet consisted of one line.

lan Campbell,

Retired GP, Louth.

E-mail: docianclagmail.com

\section{REFERENCES}

1. Jones R. AJ Cronin: novelist, GP, and visionary. $\mathrm{Br} \mathrm{J}$ Gen Pract 2015; DOI: 10.3399/bjgp15X686629.

2. Watt G. BJGPLibrary: The Citadel. Br J Gen Pract 2015; DOI: 10.3399/bjgp15X686641.

DOI: 10.3399/bjgp15X686869

\section{Correction}

In the September 2015 article by Budtz-Lilly A et al, Patient characteristics and frequency of bodily distress syndrome in primary care: a crosssectional study. Br J Gen Pract 2015; DOI: 10.3399/ bjgp15X686545, Table 1 was missing several Participant and BDS+ figures. The online version has been corrected. We apologise for this error.

DOI: 10.3399/bjgp15X687205 